\title{
Interventions to Improve Walking in Older Adults
}

\author{
Jennifer S. Brach • Jessie M. VanSwearingen
}

Published online: 26 September 2013

(C) Springer Science+Business Media New York 2013

\begin{abstract}
Interventions to improve walking in older adults have historically been multifactorial (i.e., strengthening, endurance and flexibility programs) focusing on improving the underlying impairments. These impairment-based programs have resulted in only modest improvements in walking. In older adults, walking is slow, less stable, inefficient, and the timing and coordination of stepping with postures and phases of gait is poor. We argue the timing and coordination problems are evidence of the loss of motor skill in walking. Taking a lesson from the sports world and from neurorehabilitation, taskoriented motor learning exercise is an essential component of training to improve motor skill and may be a beneficial approach to improving walking in older adults. In this article we: (1) briefly review the current literature regarding impairmentbased interventions for improving mobility, (2) discuss why the results have been only modest, and (3) suggest an alternative approach to intervention (i.e., task-oriented motor learning).
\end{abstract}

Keywords Aging $\cdot$ Walking $\cdot$ Exercise $\cdot$ Motor learning

\section{Introduction}

Walking difficulty is a common, costly problem in older adults and it contributes to loss of independence, higher rates of morbidity and increased mortality $[1-4,5 \bullet \cdot]$. Walking is a complex task that places demands on the musculoskeletal, cardiopulmonary, and nervous systems [6]. The changes that occur in walking with age are likely the result of multiple

\footnotetext{
J. S. Brach $(\bowtie) \cdot$ J. M. VanSwearingen

Department of Physical Therapy, University of Pittsburgh, 6035

Forbes Tower, Pittsburgh, PA 15260, USA

e-mail: jbrach@pitt.edu

J. M. VanSwearingen

e-mail: jessievs@pitt.edu
}

small changes in several different systems more so than the result of one catastrophic event such as a stroke or hip fracture. The walking disability develops gradually, and although many older adults are referred (or self-refer) to a geriatric specialist because of the mobility problem, the reason for the walking difficulties often cannot be identified [6].

The constellation of deficits characteristic of age-related walking problems contributes to inefficient gait [6-10]. Typically the biomechanics are altered (i.e., flexed trunk posture [11], decreased hip extension in mid to late stance $[12,13]$, and decreased ankle plantarflexion and power at push-off) $[11,13-16]$ and movement control is disrupted (i.e., reduced rate of forward momentum [17], stride length and time variability $[18,19]$, and timing issues, including a loss of the rhythm, hesitancy, and difficulty transitioning from stance to swing. swing) [17, 20, 21]. The biomechanical and movement control problems appear to interact [9]. For example, the reduced hip extension blocks the mechanical accumulation of potential energy in the limb tissues during stance to release during swing to fuel the limb forward movement, while also eliminating the hip extension, movement-related feedback stepping signal for the transition from stance to step [17, 22-27].

Interventions to improve walking have historically been multifactorial (i.e., strengthening, endurance and flexibility programs) focusing on improving the underlying impairments of the systems involved. These multifactorial impairmentbased programs have resulted in only modest improvements in walking (eg an approximate $5 \%$ increase in gait speed, with a range of 0-16\%) [28-39]. The questions are: "Why are the results suboptimal?" and "Can we [or can't we] do better?".

Whether contributors to or consequences of the age-related walking problems, walking is slow [17], less stable [40], inefficient [41], and the timing and coordination of stepping with postures and phases of gait is poor [42-44]. We argue the timing and coordination problems are evidence of the loss of 
motor skill in walking, more so than a decrease in physiological reserve capacities [muscle strength, motion, and endurance] for walking alone. The loss of motor skill related, high energy cost of walking (e.g., inefficient) is a major factor in the age-related decline in physical function and activity for older adults. Taking a lesson from the sports world and from neurorehabilitation, task-oriented motor skill exercise is the essential component of exercise training to improve motor task performance [45, 46••, 47•]. How do the most skilled movers at their sport prepare for their sport specific skilled tasks? While sport specific skilled movers may exercise to build a foundation of muscle strength, flexibility and endurance capacity for their sport, no athlete steps to the plate with a bat in hand, raises the basketball to the hoop, or tees up the golf ball without substantial task-oriented exercise training. In other words, if walking is the problem, then the intervention should primarily focus on the task of walking through motor skill-based exercise and not on an impairment-based exercise intervention alone.

The purpose of this article as to (1) briefly review the current literature regarding impairment-based intervention approaches for improving mobility in older adults, (2) discuss why the results have been suboptimal (only modest), and (3) suggest an alternative approach to intervention to improve mobility in older adults (i.e., task-oriented motor learning).

\section{Impairment-based Interventions to Improve Mobility}

Multifactorial Impairment-Based Walking Exercise The multifactorial impairment-based therapeutic approach to improve age-related walking problems is to 'fix' the impairments of lower extremity weakness, flexibility, and endurance related to walking difficulties. The 'fix' involves therapeutic exercise to enhance capacities of muscle strength, range of motion, and aerobic conditioning [48]. Resistance exercises are used to strengthen weak lower extremity muscles for their functions as prime movers of the limbs, as well as for their actions as synergists to stabilize the trunk, or as antagonists, preprogrammed to decelerate limb movement facilitated by the prime mover. Exercises to improve muscle strength and power can enhance the ability of a weak lower limb muscle, such as the ankle plantarflexors to initiate ground reaction forces or the hip abductor muscles to control medial lateral movements during walking. Stretching exercises to increase joint range of motion (ROM) are performed to allow the older adult to: (1) attain specific postures of the limbs or trunk necessary to allow for the muscle forces generated to result in the desired direction of forward propulsion [e.g., plantarflexion ROM], (2) the desired length of muscles for optimal activation (e.g., dorsiflexion ROM at heel strike, lengthening the calf muscles to facilitate their subsequent activation), and (3) appropriate movement-related feedback to the nervous system controlling and adapting stepping patterns [e.g., hip extension]. Aerobic conditioning exercise enhances the delivery and extraction of oxygen to the muscles, necessary to sustain the repeated pattern of muscle activation in walking (Table 1).

While focus of the impairment-based exercise approach to age-related walking problems is to remedy the reduced capacity of the body systems that contribute to the movements in gait, in the context of walking the rationale for the approach can be inadequate. In our clinical experience, many older adults with age-related walking difficulties demonstrate adequate muscle force production for mobility. The relation of muscle strength to gait performance is modest at best [49], and strengthening exercises have only minimal effect on walking ability [50].Lower extremity range of motion deficits noted among older adults have often been small, and walking typically involves limited range of motion of the lower limb joints $[13,15]$. Interventions targeted at improving ROM have resulted in little change in gait characteristics of older adults, particularly with the joint motion during walking $[15,51]$. Enhancing aerobic capacity may provide the energy needed to sustain the muscle activity the older adult uses for walking and reduce restriction of walking activity in prolonged walking conditions $[48,52]$. However, there is little reason to believe aerobic conditioning would impact the agerelated changes in brief bouts of walking characteristic of activities of daily living (ADLs) and during performance of a short [e.g., $4 \mathrm{~m}$ ] timed walk (the latter the observational method by which age-related walking changes have most often been described) [2-4].

In addition to addressing impairments, multifactorial approaches typically include progressive ambulation training. In progressive ambulation exercise component tasks of walking (e.g. propulsion, weight-shifting of the center of mass, toe clearance during swing, weight acceptance at heel strike) are broken down and practiced individually, using visual, verbal and manual cueing [53]. The older adult is provided feedback on the walking components to facilitate their ability to recognize the incorrect actions and make conscious choices to correct the walking pattern. Increased demands for cognitive processing are difficult for older adults, particularly related to tasks that require recognition of peripheral sensory input, specifically when a shift is required to relate sensory input to a self-organized, walking movement plan [20, 54-57]. Among older adults, key factors in slowed movement performance are signal recognition and central plan processing [58, 59]. Slowed movement performance while participating in gait training, may accentuate the timing and coordination problems in walking $[9,17,20]$. Thus, multifactorial, impairment-based exercise aims to increase physiologic capacity in body systems that contribute to walking, but does not include task specific exercise necessary to make use of the 
Table 1 Components of impairment-based and task oriented motor learning interventions

\begin{tabular}{|c|c|c|}
\hline Component & Purpose & Sample exercise \\
\hline Resistance exercise & $\begin{array}{l}\text { Improve strength and power of weak lower } \\
\text { extremity muscles used in walking. }\end{array}$ & Repeated chair stand \\
\hline Stretching & $\begin{array}{l}\text { Increase joint range of motion to attain specific } \\
\text { postures of the limb during walking }\end{array}$ & Stretching of the dorsi-flexors \\
\hline Aerobic conditioning & $\begin{array}{l}\text { Enhance the delivery and extraction of oxygen } \\
\text { to the muscles used in walking }\end{array}$ & Cycling on a stationary bike \\
\hline Progressive ambulation training & $\begin{array}{l}\text { Practice components of walking to facilitate } \\
\text { ability to recognize incorrect actions so that } \\
\text { they can be consciously corrected }\end{array}$ & $\begin{array}{l}\text { Repeated practice of push-off or weight } \\
\text { shifting of the center of mass }\end{array}$ \\
\hline \multicolumn{3}{|c|}{ Task Oriented Motor Learning: Build a "Better Engine" } \\
\hline Component & Purpose & Sample exercise \\
\hline Defined movement goal & $\begin{array}{l}\text { Limits degrees of freedom and reduces } \\
\text { conscious attention }\end{array}$ & $\begin{array}{l}\text { Stepping patterns such as stepping forward } \\
\text { and across. Walking to set speed using } \\
\text { music or metronome }\end{array}$ \\
\hline $\begin{array}{l}\text { Movement to gain knowledge of } \\
\text { muscles and postures }\end{array}$ & $\begin{array}{l}\text { Facilitate smooth switching between agonists } \\
\text { and antagonist muscle groups during gait }\end{array}$ & $\begin{array}{l}\text { Stepping backward and across prior to } \\
\text { stepping forward. }\end{array}$ \\
\hline $\begin{array}{l}\text { Practice to correct errors in } \\
\text { movement, develop and adjust } \\
\text { motor plans }\end{array}$ & $\begin{array}{l}\text { Accurate practice to facilitate neuroplastic } \\
\text { changes or skill acquisition }\end{array}$ & Treadmill walking \\
\hline $\begin{array}{l}\text { Challenge to select optimal } \\
\text { motor plan }\end{array}$ & $\begin{array}{l}\text { Challenges accuracy and amplitude to facilitate } \\
\text { motor skill acquisition. Sets criterion } \\
\text { for performance. }\end{array}$ & $\begin{array}{l}\text { Varying selection of motor plan during walking } \\
\text { such as changing the direction of walking an } \\
\text { oval path or spiral }\end{array}$ \\
\hline
\end{tabular}

physiological capacity in body systems (i.e., musculoskeletal and cardiopulmonary systems) for the walking. The result is a bigger engine for walking and maximum performance; the ability to use the excess capacity to tolerate the agerelated gait abnormalities and high energy cost of poor walking (Fig. 1).

\section{Alternative Approach - Task-oriented Motor Learning}

Task-Oriented Motor Skill-Based Walking Exercise Motor skill exercise for walking is task-oriented, motor sequence learning, intended to improve the older adult's appropriate motor plan selection from an enhanced repertoire of motor plans for walking. Changes in the capacities of body systems [48] necessitates a change in the choice of motor plans to meet the performance demands $[60,61]$. To make the appropriate motor plan selection, the brain needs continual and relevant movement experiences. To make appropriate changes in the selection of motor plans, the brain needs to be updated about the body capacities through continued recent and relevant movement experiences in walking [61].

Welford [60] defined motor skill as the selection of the minimum capacities to meet task demands, or the most appropriate motor plan for the task. The highly skilled or expert mover uses the minimum neural, muscle and joint motion capacities for successful task performance and because only the minimum capacities are selected, skilled movement is efficient [62]. For the highly skilled, at the motor task, movement acceleration and deceleration are planned together, the movement is continuous, without guidance, and as a result the movement is usually fast and efficient. In comparison, the less skilled, rely on non-programmed (discontinuous) movements that require feedback and the result is slow and inefficient movement [61]. Motor skill-based walking exercise has increased efficiency and speed of walking [63, 64•]. Motor skill in well-learned movement tasks is maintained through information gained by the person's sensing and moving environmental experiences. The regular and relevant experiences serve to adapt and refresh motor programs. Adjustments are made for changes in the limbs, muscles and posture, which enables the skilled mover to focus on the movement goal, while spinal and supraspinal motor centers organize and implement successful movement strategies [61, 65, 66].

Important components to task-oriented, motor skill exercise are combining different conditions of performance, body position and task demands to yield variations in exercise complexity and the skill required [67]. When the participant accomplishes the goal of the motor task, the successful performance rewards and reinforces the motor plan selection [66]. Motor skill-based exercise includes: (1) a defined movement goal; (2) movement to gain knowledge of muscles and postures (i.e., implicit motor learning or movement awareness); (3) practice to correct errors in movement, develop and adjust 


\section{Impairment Based Program}

\section{Motor Learning Program}

"Build a Bigger Engine"

In an ENGINE: need to increase displacement in all cylinders and accommodate more gas to be burned during each revolution of the engine

- Increase \# cylinders (V6 vs. V8)

- Make cylinders bigger

- Increase compression ratio

\section{"Run with More Horsepower"}

In a PERSON: increase capacity of musculoskeletal and cardiopulmonary systems

- Increase muscle strength and power

- Increase joint range of motion

- Enhance delivery and extraction of oxygen

\section{"Maximum Performance"}

Fig. 1 Building a bigger engine versus a better engine: A comparison between impairment-based and task-specific motor learning exercise programs. We relate differences in the exercise programs to differences in building an engine for maximum versus optimal performance. The

motor plans, and 4) challenge to select the optimal motor plan (Table 1) [61]. The following are specific examples of motor skill-based exercise principles applied to walking.

Defined Movement Goal Defining the goal of the task limits the degrees of freedom and enhances the probability that the person will generate the appropriate sequence of muscles and movements. The defined goal links the motor sequence generated to the neural circuit for the intended task $[68 \bullet \bullet, 69,70]$. Motor sequence learning of the pattern and timing of muscle activation for the intended task occurs primarily without conscious attention to the recruitment of specific muscles and timing of the movement series. For example, a defined goal for step initiation in gait, such as 'step across' and toward the forward line of progression of the stance limb, enhances forward momentum in the stepping pattern of gait. By accomplishing the step across task goal, the center of mass

"Build a Better Engine"

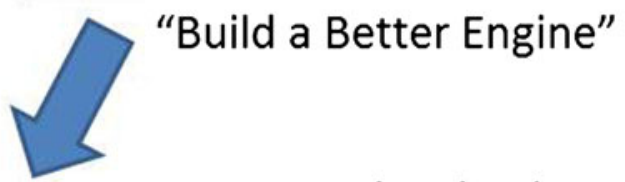

In an ENGINE: clean air and gas need to be driven to car's cylinders for combustion when needed

- Tune-up system components (spark plugs, air filters, hoses, belts, etc)

- Check timing controls

- Optimize idling ratio

\section{"Run More Efficiently"}

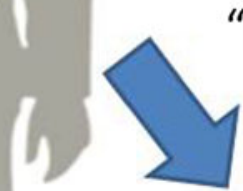

In a PERSON: integrate movement and postures, improve efficiency

- Re-align biomechanical and neuromotor control

- Improve motor skill

- Strengthen motor programs

- Improve feedback for adjusting movements

"Optimal Performance" impairment-based program results in greater physiological capacity in body systems that can be used for walking (i.e., maximum performance). The motor learning program results in a more efficient use of physiological capacity in body systems for walking (i.e., optimal performance) of the body accelerates toward the stance limb and loads the limb through midstance. Stance limb loading not only facilitates plantarflexor power while the limb accelerates behind the body, but the loading also accelerates the thigh into hip extension - the neural signal for stepping. The step across task goal facilitates activation of the abductors on the limb in transition to swing with the adductors on the limb in transition to stance and accelerates the center of mass of the body forward and toward the stance limb [17]. During walking, defined goals for walking that promote forward momentum by the interaction of the limbs with the ground sustains the pattern of stepping and reduces the need to generate individual steps that tax balance control mechanisms [11, 17, 40]. Forward momentum in walking is also facilitated by a defined goal of a gait speed [71•] or a cadence to maintain throughout walking and can be accomplished by the use of a metronome or the rhythm of music [72-74]. The combined activation 
of the hip abductors of one limb with the adductor muscles of the opposite limb is facilitated by a curved path goal for walking [63, 75-77].

Move to Gain Knowledge Walking activities that involve alternating the direction of trunk and limb movements simulate the smooth switching between agonist and antagonist muscle groups in gait. In sitting, a forward reach on a diagonal with the upper body leaning on to an exercise ball, followed by reversal of the movement, reproduces the pattern of trunk movements and generates the movement-related feedback characteristic of the alternating locomotor pattern in walking. A step backward and across prior to a step forward and across exercise induces the muscle pattern and limb loading necessary to generate momentum forward toward the limb preparing for stance. The stepping exercise provides the experience of moving the body center of mass without asking the person to 'think' about weight shifting and progression. Walking circular paths, alternating clockwise and counterclockwise directions provide similar patterned muscle activation and limb loading experiences as in the stepping exercises but in the context of walking.

Practice to Refine and Develop a Repertoire of Motor Plans Accurate repetition [eg practice] of the motor plan for the walking drives experience dependent changes in neurons and their connections, or the neuroplastic changes characteristic of motor skill acquisition) [69, 78-80]. Repetition of stepping and walking pattern activities in one direction or side only (e.g., 10 repetitions), then to the opposite side (e.g., 10 repetitions), prior to switching the exercise tasks more frequently progressing to switching on every repetition is a method for promoting accuracy before advancing to the more difficult skill of continuous switching movement plans. Components of the motor skill for walking practiced in one exercise task are incorporated into subsequent exercises - for example "step across" muscle pattern activation could be practiced again in curved path walking patterns. Treadmill assisted-walking provides accurate practice at a designated speed [goal]. The moving belt of the treadmill facilitates consistent step timing and the hip extension movement that elicits the neural signal for stepping. Demands on cognitive processing are minimal as treadmill-assisted walking is motor skill walking practice 'by doing' [42, 81-84].

Challenges to Select the Optimal Motor Plan In addition to the switching between movement directions and alternating movement patterns described above (move to gain knowledge), motor skill acquisition can be enhanced by challenges of accuracy and amplitude and varying the demand for accuracy, amplitude and direction in walking motor tasks. Oval [curved] walking paths can be made narrower, or progressively smaller ovals as in a spiral walking pattern. The goal for consistent speed or pace is maintained for the curve and the straighter parts of the oval and spiral paths. Varying the selection of motor plans while walking can be implemented by: (1) changing directions on the oval or spiral paths; (2) walking a figure-of-eight path [curve direction changes at each end of the ' 8 ']; and (3) walking a serpentine path.

The challenge to select the optimal motor plan for the walking conditions also sets a criterion for performance. The performer's ability to recognize success in walking may be a key factor in the maintenance of intervention-related improvements [85, 86] in walking [71•]. The defined movement goal for the repetitive task-oriented exercise provides a performance criterion that allows the performer to clearly recognize success throughout the practice as well as at the completion of an entire intervention episode. Visual feedback [87••], verbal positive reinforcement of the task $[71 \bullet, 88]$, and reinforcement in a virtual reality environment [86] are all examples of success/reward recognition task-oriented exercise strategies that have had a positive impact on the motor skill of walking. Interventions that focus on timing and coordination of gait reduced the energy cost of walking and increased gait speed $[63,64 \cdot, 89]$. Intervention strategies that facilitates the performer's ability to recognize successful walking performance may positively influence the sustainability of the skilled walking ability. Among mobility-limited older adults, the increased walking confidence outcome of task-oriented but not the impairment-oriented walking exercise may be attributed to the characteristics of the motor skill-based walking exercise approach $\left[63,90^{\bullet}\right]$.

In summary, the task-oriented motor learning intervention aims to improve the motor skill of walking by re-aligning biomechanical and neuromotor control, strengthening motor programs, and improving feedback for adjusting movements. In a sense it is comparable to a "tune-up" of an engine for optimal performance. The result is a more efficient system for walking which requires less energy and can last longer (Fig. 1). Older adults who are skilled, efficient walkers likely tire less easily and thus have the ability to participate in many life activities [63, 64•, 90•].

\section{Evidence Supporting Task-Oriented Motor Learning Exercise}

We recently conducted two randomized clinical trials to examine the impact of task-oriented motor learning exercise on mobility in two distinct groups of older adults, those with moderate mobility difficulty (the RESTORE study) [63, 90.] and those with mild subclinical mobility limitations 
(the PRIME study) [64•]. In the RESTORE study, 47 older adults with slow and variable gait were randomly assigned to either an impairment-based or a task-oriented motor learning exercise program. These older adults walked slowly, mean gait speed $0.85 \mathrm{~m} / \mathrm{s}$, with ineffecient gait (i.e. mean baseline energy cost of walking was $0.30 \mathrm{~mL} / \mathrm{kg} / \mathrm{m}$, almost twice the energy cost of normal walking). The exercise was delivered by a physical therapist and lasted one hour, twice a week for 12 weeks. At the end of 12 weeks, older adults in the taskspecific group had greater improvements in the energy cost of walking, gait quality, walking confidence, and physical function compared to older adults in the impairment-based group $[63,90 \bullet]$.

The PRIME study included 40 older adults with subclinical gait dysfunction defined as near normal gait speed and impaired skill in walking. Though their mean baseline gait speed of $1.18 \mathrm{~m} / \mathrm{s}$ was near normal (i.e., $1.2-1.3 \mathrm{~m} / \mathrm{s}$ ) their baseline energy cost of walking of $0.22 \mathrm{~mL} / \mathrm{kg} / \mathrm{m}$ was nearly $50 \%$ greater than the $0.15-\mathrm{mL} / \mathrm{kg} / \mathrm{m}$ energy cost of walking in young adults indicating an inefficient walking pattern. Subjects were randomly assigned to either an impairmentbased or a task-oriented motor learning exercise program that met twice weekly for twelve weeks. After the intervention, the subjects in the task-oriented group improved more than the subjects in the impairment-based group in gait speed and measures of motor skill in walking. In fact, the task-oriented group improved more than twice as much in gait speed (i.e., $0.13 \mathrm{~m} / \mathrm{s}$ versus $0.05 \mathrm{~m} / \mathrm{s}$ ) as the impairment-based group. Although not statistically significant, the difference in change in energy cost of walking between the groups was clinically meaningful with the task-oriented group demonstrating greater improvements than the impairment-based group [64•]. In older adults with either mild (PRIME) or moderate (RESTORE) gait dysfunction, a task-oriented motor learning exercise program resulted in greater improvements in several mobility indicators than an impairment-based program. The task-oriented training resulted in older adults who walked faster, more efficiently with improved motor skill and confidence (i.e., better walking ability).

\section{Conclusion}

Age-related walking problems may be responsible for greater mortality and morbidity of older adults than acute illness and disease [7]. Multicomponent impairment-based walking exercise can enhance strength, flexibility and endurance capacities important for walking (a 'bigger walking machine'), but not necessarily better walking ability. The outcome of task-oriented motor learning walking exercise is the timing and coordination for better walking ability-a 'well-tuned walking machine'.
Acknowledgements This work was supported by the Pittsburgh Older Americans Independence Center (NIA P30 AG024827) and Beeson Career Development Award (NIA K23 AG026766).

\section{Compliance with Ethics Guidelines}

Conflict of Interest Jennifer S. Brach and Jessie M. VanSwearingen declare that they have no conflict of interest.

Human and Animal Rights and Informed Consent This article does not contain any studies with human or animal subjects performed by any of the authors.

\section{References}

Papers of particular interest, published recently, have been highlighted as:

- Of importance

-. Of major importance

1. Cesari M, Kritchevsky S, Bauer DC, et al. Prognostic value of usual gait speed in well-functioning older people-results from the Health, Aging and Body Composition Study. J Am Geriatr Soc. 2005;53(10): 1675-80.

2. Guralnik JM, Ferrucci L, Pieper C, et al. Lower extremity function and subsequent disability: consistency across studies, predictive models, and value of gait speed alone compared with the short physical performance battery. J Gerontol Med Sci. 2000; 55A:M221-31.

3. Guralnik JM, Simonsick EM, Ferrucci L, et al. A short physical performance battery assessing lower extremity function: Association with self-reported disability and prediction of mortality and nursing home admission. J Gerontol. 1994;49:M85-94.

4. Guralnik JM, Ferrucci L, Simonsick EM, Salive ME, Wallace RB. Lower extremity function in persons over the age of 70 years as a predictor of subsequent disability. New Engl J Med. 1995;332:556-61.

5. • Studenski S, Perera S, Patel K, et al. Gait speed and survival in older adults. JAMA. 2011;305(1):50-8. This paper examines the association between gait speed and survival using a pooled analysis of 9 cohort studies with individual data from 34,485 community-dwelling older adults. Predicted survival based on age, sex and gait speed was as accurate as predicted by age, sex, chronic conditions, smoking history, blood pressure, body mass index, and hospitalization.

6. Ferrucci L, Baninelli S, Benvenuti E, et al. Subsystems contributing to the decline in ability to walk: Bridging the gap between epidemiology and geriatric practice in the InCHIANTI study. J Am Geriatr Soc. 2000;48(12):1618-25.

7. Guralnik JM, Ferrucci L, Balfour JL, Volpato S, Di Iorio A. Progressive versus catastrophic loss of the abilit to walk: Implications for the prevention of mobility loss. J Am Geriatr Soc. 2001;49:1463-70.

8. Hausdorff JM, Edelberg HK, Mitchell SL, Goldberger AL, Wei JY. Increased gait unsteadiness in community-dwelling elderly fallers. Arch Phys Med Rehabil. 1997;78(3):278-83.

9. Hausdorff JM, Ashkenazy Y, Peng CK, Ivanov PC, Stanley HE, Goldberger AL. When walking becomes random walking: fractal analysis and modeling of gait rhythm fluctuations. Physica A. 2001;302(1-4):138-47.

10. Rantanen T, Guralnik JM, Ferrucci L, et al. Coimpairments as predictors of severe walking disability in older women. J Am Geriatr Soc. 2001;49:21-7. 
11. McGibbon CA, Krebs D. Age-related changes in lower trunk coordination and energy transfer during gait. J Neurophysiol. 2001;85:1923-31.

12. Kerrigan D, Lee LW, Collins JJ, Riley PO. Reduced hip extension during walking: healthy elderly and fallers versus young adults. Arch Phys Med Rehabil. 2001;82(1):26-30.

13. Kerrigan D, Todd MK, Della Croce U, Lipsitz LA, Collins JJ. Biomechanical gait alterations independent of speed in the healthy elderly: evidence for specific limiting impairments. Arch Phys Med Rehabil. 1998;79(3):317-22.

14. Lewis GN, Byblow WD, Walt SE. Stride Length Regulation in Parkinson's Disease: The use of Extrinsic, Visual Cues. Brain. 2000;123:2077-90.

15. McGibbon CA. Toward a better understanding of gait changes with age and disablement: Neuromuscular adaption. Exerc Sports Sci Rev. 2003;31:102-8.

16. DeVita P, Hortobagyi T. Age Causes a Redistribution of Joint Torques and Powers During Gait. J Appl Physiol. 2000;88:1804-11.

17. Polcyn AF, Lipsitz LA, Kerrigan CD, Collins JJ. Age-related changes in the initiation of gait: degradation of central mechanisms for momentum generation. Arch Phys Med Rehabil. 1998;79:1582-9.

18. Hausdorff JM, Nelson ME, Kaliton D, et al. Etiology and Modification of Gait Instability in Older Adults: A Randomized Controlled Trial of Exercise. J Appl Physiol. 2001;90:2117-29.

19. Hausdorff JM, Rios DA, Edelberg HK. Gait variability and fall risk in community-living older adults: a 1-year prospective study. Arch Phys Med Rehabil. 2001;82(8):1050-6.

20. Morgan M, Phillips J, Bradshaw J, Mattingley J, Iansek R, Bradshaw J. Age-Related Motor Slowness: Simply Strategic? Journal of Gerontology. 1994;49(3):M133-9.

21. Rogers MW, Kulkulka CG, Soderberg GL. Age-related changes in postural responses preceding rapid self-paced and reaction time arm movements. J Gerontol. 1992;47:M159-65.

22. Dickinson MH, Farley CT, Full RJ, Koehl MAR, Kram R, Lehman S. How animals move: An integrative view. Science. 2000;288(5463):100-6.

23. Donelan JM, Kram R. The effect of reduced gravity on the kinematics of human walking: A test of the dynamic similarlity hypothesis for locomotion. J Exp Biol. 1997;200:3193-201.

24. Capaday C. The special nature of human walking and its neural control. Trends in Neurosciences. 2002;25(7):370-6.

25. Capaday C. Force-feedback during human walking. Trend Neurosci. 2001;24:10.

26. Pang M, Yang JF. Interlimb Co-ordination in Human Infant Stepping. Journal of Physiology. 2001;533(2):617-25.

27. Boda WL et al. Comparison of gait mechanics adn force generation during upright treadmill and supine LPNP exercise. Med Sci Sports Exer. 1996;28:S87.

28. Judge JO, Underwood M, Gennosa T. Exercise to improve gait velocity in older persons. Arch Phys Med Rehabil. 1993;74(4):400-6.

29. Brown M, Holloszy JO. Effects of a low intensity exercise program on selected physical performance characteristics of 60- to 71-year olds. Aging (Milano). 1991;3:129-39.

30. Fiatarone MA, O'Neill EF, Ryan ND, et al. Exercise training and nutritional supplementation for physical frailty in very elderly people. New Engl J Med. 1994;330:1769-75.

31. LIFE Study Investigators. Effects of a physical activity intervention on measures of physical performance: results of the Lifestyle Interventions and independence for elders pilot (LIFE-P) study. J Gerontol Med Sci. 2006;61A:1157-65.

32. Sauvage LR, Myklebust BM, Crow-Pan J, et al. A clinical trial of strengthening and aerobic exercise to improve gait and balance in elderly male nursing home residents. Am J Phys Med Rehabil. 1992;71:333-42.

33. Topp R, Mikesky A, Wigglesworth J, Holt W, Edwards JE. The effect of a 12-week dynamic resistance strength training program on gait velocity and balance of older adults. Gerontologist. 1993;33(4):501-6.
34. Bean JF, Herman S, Kiely DK, et al. Increased velocity exercise specific to task training: a pilot study exploring effects on leg power, balance, and mobility in community dwelling older women. J Am Geriatr Soc. 2004;52(5):799-804.

35. Buchner DM, Cress ME, de Lateur BJ, et al. A comparison of the effects of three types of endurance training on balance and other fall risk factors in older adults. Aging Clin Exp Res. 1997;9:112-9.

36. Buchner DM, Cress ME, de Lateur BJ, et al. The effects of strength and endurance training on gait, balance, fall risk, and health services use in community-living older adults. J Gerontol Med Sci. 1997;52A(4):M218-24.

37. Helbostad JL, Sletvold O, Moe-Nilssen R. Home training with and without additional group training in physically frail older people living at home: effect on health-related quality of life and ambulation. Clinical Rehabilitation. 2004;18:498-508.

38. Wolf SL, O'Grady M, Easley KA, Guo Y, Kressig RW, Kutner M. The influence of intense Tai Chi training on physical performance and hemodynamic outcomes in transitionally frail, older adults. J Gerontol Med Sci. 2006;61A:184-9.

39. Manini T, Marko M, VanArnam T, et al. Efficacy of resistance and task-specific exercise in older adults who modify tasks of everyday life. J Gerontol Med Sci. 2007;62A:616-23.

40. Gabell A, Nayak USL. The effect of age and variability in gait. Journal of Gerontology. 1984;39(6):662-6.

41. Waters R. Energy Expenditure. In: Perry J, editor. Gait Analysis:normal and pathologic function. Thorofare NJ: Slack Inc; 2004. p. 443-89.

42. Macko RF, Smith GV, Dobrovolny NA, Sorkin JD, Goldeberg AP, Silver KH. Treadmill training improves fitness reserve in chronic stroke patients. Arch Phys Med Rehabil. 2001;82:879-84.

43. Bernardi M, Macaluso A, Sproviero E, et al. Cost of Walking and Locomotor Impairment. J Electromyogr Kinesiol. 1999;9(2):149-57.

44. Gersten J, Orr W. External work of walking in hemiparetic patients. Scan J Rehabil Med. 1971;3:85-8.

45. Handford C, Davids K, Bennett S, Button C. Skill acquisition in sport: some applications of an evolving practice ecology. Journal of Sports Science. 1997;15(6):621-40.

46. ••DePaul VG, Wishart LR, Richardson J, Lee TD, Thabane L. Varied overground walking-task practice versus body-weight-supported treadmill training in ambulatory adults within one year of stroke: a randomized controlled trial protocol. BMC Neurol 2011;11(129). The authors operationally define two different walking interventions and the differences in the rationale for each in persons poststroke: a varied overground motor learning walking program and a high repetition body weight supported treadmill walking program. The description of the design of the proposed comparative efficacy trial illustrates a combination of evidence and scientific rationale in the design and planned interpretation of findings.

47. • Jonsdottir J, Cattaneo D, Recalcati M, et al. Task-oriented biofeedback to improve gait in individuals with chronic stroke: motor learning approach. Neurorehabil Neural Repair. 2010;24(5):478-85. The authors describe the integration of electromyographic biofeedback (EMG-BFB) to define the goal of the gait exercise - gastrocnemius muscle force production in an intervention approach based on principles of motor learning. While the intrasession defined goal is based on muscle force production, enhancing gait speed is the targeted outcome of the motor learning intervention.

48. Studenski S. Mobility. Principles in Geriatrics and Gerontology. 5th ed. 2004.

49. Brown M, Sinacore DR, Host H. The relationship of strength to function in the older adult. J Gerontol. 1995;50A:55-9.

50. Chandler JM, Duncan PW, Kochersberger G, Studenski S. Is lower extremity strength gain associated with improvement in physical performance and disability in frail, community-dwelling elders? Arch Phys Med Rehabil. 1998;79(1):24-30. 
51. Kerrigan CD, Xenopoulos-Oddsson A, Sullivan MJ, Lelas JJ, Riley PO. Effect of a hip flexor-stretching program on gait in the elderly. Arch Phys Med Rehabil. 2003;84:1-6.

52. Harada ND, Chiu V, Stewart AL. Mobility-related function in older adults: assessment with a 6-minute walk test. Arch Phys Med Rehabil. 1999;80:837-41.

53. Shumway-Cook A, Woollacott MH. Motor Control; Theory and Practical Applications. 2nd ed. Philadelphia, PA: Lippincott Williams \& Wilkins; 2001.

54. Welford AT. Reaction time, speed of performance, and age. Ann NY Acad Sci. 2004;515:1-17.

55. Bock O, Schneider S. Sensorimotor adaptation in young and elderly humans. Neurosci Biobehav Rev. 2002;26:761-7.

56. Wulf G, Chiviacowsky S, Lewthwaite R. Altering mindset can enhance motor learning in older adults. Psychol Aging. 2012;27(1):14-21.

57. Wulf G, Shea C, Lewthwaite R. Motor skill learning and performance: a review of influential factors. Med Educ. 2010;44(1):75-84.

58. Welford AT. Between bodily performance and slowing with age. Exp Aging Res. 1984;10:73-88

59. Goggin NL, Stelmach GE. Age-related differences in kinematic analysis of precued movements. Can J Aging. 1990;9:371-85.

60. Welford AT. Motor Skills and Aging. In: Mortimer JA, Pirozzolo FJ, Maletta GJ, editors. The Aging motor System. New York: Praeger Publishers; 1982. p. 152-87.

61. Brooks VB. The Neural Basis of Motor Control. New York: Oxford University Press; 1986.

62. McArdle WD, Katch FI, Katch VL. Exercise Physiology: Energy, Nutrition, and Human Perofrmance. 5th ed. Baltimore, MD: Lippincott Williams \& Williams; 2001.

63. VanSwearingen JM, Perera S, Brach JS, Cham R, Rosano C, Studenski SA. A randomized trial of two forms of therapeutic activity to improve walking: effect on the energy cost of walking. J Gerontol A Biol Sci Med Sc. 2009;64A:1190-8.

64. - Brach JS, VanSwearingen JM, Perera S, Wert DM, Studenski SA. Motor learning versus standard walking exercise in older adults with subclinical gait dysfunction: A randomized clinical trial. $J \mathrm{Am}$ Geriatr Soc 2013; In press. A single-blind randomized trial to compare motor learning versus standard exercise on measures of mobility and perceived function and disability in older adults with subclinical gait dysfunction. Motor learning exercise improved gait speed and motor skill more than standard exercise. Both groups improved in endurance.

65. Bizzi E, Tresch MC, Saltiel P, D'Avella A. New perspectives on spinal motor systems. Neuroscience. 2000;1:101-8.

66. Schmidt RA. Organizing and Scheduling Prcatice. In: Schmidt RA, editor. Motor Learning and Practice: From Principles to Practice. Champaign, IL: Human Kinetics Books; 1991. p. 199-225.

67. Gentile A. Skill acquisition: action, movement, and neuromotor processes. In: Carr JH, Shepherd RB, Gordon J, Gentile AM, Held JM, editors. Movement Sciences. 1st ed. Rockville: Aspen Publishers; 1987. p. 93-154.

68. •• Cramer SC, Sur M, Dobkin BH, et al. Harnassing neuroplasticity for clinical applications. Brain. 2011;134:1591-609. An extensive review and update on neuroplasticity from the perspective of potential therapies, including physical activity and rehabilitation exercise induced motor learning. Current evidence and potential mechanisms for physical and cognitive training, neuropharmacologic, brain stimulation, and combinations of several therapies to induce neuroplasticity are presented.

69. Dobkin BH. Functional Rewiring of Brain and Spinal Cord after Injury: The three Rs of neural repair and neurological rehabilitation. Curr Opin Neurol. 2000;13:655-9.

70. Dobkin BH. Motor rehabilitation after stroke, traumatic brain, and spinal cord injury: common denominators within recent clinical trials. Curr Opin Neurol. 2009;22:563-9.
71. • Dobkin BH, Plummer-D'Amato P, Elashoff R, Lee J, SIRROWS Group. International randomized clinical trial, stroke inpatient rehabilitation with reinforcement of walking speed (SIRROWS), improves outcomes. Neurorehabil Neural Repair. 2010;24:235-42. An innovative, clinical efficacy trial conducted in the usual clinical in which the benefits of daily feedback about walking performance and positive reinforcement of meeting the defined goal for walking practice. Verbal feedback of once daily fast as comfortable gait speed performance and encouragement for progress resulted in greater improvement in gait speed than no feedback or reinforcement but the walking rehabilitation practice.

72. Ledger L, Galvin R, Lynch D, Stokes EK. A randomised controlled trial evaluating the effect of an individual auditory cueing device on freezing and gait speed in people with Parkinson's disease. BMC Neurol. 2008;46:1-6.

73. Nieuwboer A, Kwakkel G, Rochester L, et al. Impact of a therapeutic curing program in the home on gait related mobility in Parkinson's disease. J Neurol Neurosurg Psych. 2007;78:134-40.

74. Spaulding SJ, Barber B, Colby M, Cormack B, Mick T, Jenkins ME. Cueing and gait improvement aomng people with Parkinson's disease: a meta-analysis. Arch Phys Med Rehabil. 2013;94:562-70.

75. Courtine G, Schieppati M. Human walking along a curved path. I. Body trajectory, segment orientation and the effect of vision. Euro J Neuro. 2003;18:177-90.

76. Hess RJ, Brach JS, Piva SR, VanSwearingen JM. Walking skill can be assessed in older adults: Validity of figure-of- 8 walk test. Phys Ther. 2010;90(1):89-99.

77. Kiriyama K, Warabi T, Kato M, Yoshida T, Kokayashi N. Mediallateral balance during stance phase of straight and circular walking of human subjects. Neuroscience Letters. 2005;388:91-5.

78. Doyon J, Benali H. Reorganization and plasticity in the adult brain during learning of motor skills. Curr Opin Neurol. 2005;15:161-7.

79. Doyon J. Motor sequence learning and movement disorders. Curr Opin Neurol. 2008;21:478-83.

80. Seidler RD, Noll DC. Neuroanatomical correlates of motor acquisition and motor transfer. J Neurophysiol. 2008;99:1836-45.

81. Lovely RG, Gregor RJ, Roy RR, Edgerton VR. Effects of training on the recovery of full-weight bearing stepping in the adult spinal cat. Experimental Neurology. 1986;92:421-35.

82. Maegele M, Muller S, Wernig A, Edgerton RV, Harkema SJ. Recruitment of spinal motor pools during voluntary movements versus stepping after human spinal cord injury. J Neurotrauma. 2002;19(10):1217-29.

83. Macko RF, DeSouza CA, Tretter LD, et al. Treadmill aerobic exercise training reduces the energy expenditure and cardiovascular demands of hemiparetic gait in chronic stroke patients: A preliminary report. Stroke. 1997;28:326-30.

84. Giszter SF, Kargo WJ, Davies M, Shibayama M. Fetal transplants rescue axial muscle representations in M1 cortex of neonatally transected rats that develop weight support. J Neurophysiol. 1998;80:3021-30.

85. Page SJ, Szarflarski JP, Eliassen JC, Pan H, Cramer SC. Cortical plasticity following motor skill learning during mental practice in stroke. Neurorehabil Neural Repair. 2009;23:382-8.

86. Piron L, Turolla A, Agostini M, et al. Motor learning principles for rehabilitation: a pilot randomzied controlled study in poststroke patients. Neurorehabil Neural Repair. 2010;24:501-8.

87. • Massaad F, Lejeune TM, Detrembleur C. Reducing the energy cost of hemiparetic gait using the center of mass feedback: a pilot study. Neurorehabil Neural Repair. 2010;24:338-47. Patients were provided visual feedback of the center of mass vertical displacement during treadmill walking with instructions to reduce the displacement. The intervention approach illustrates the benefits of a defined goal, accurate practice and the reward of knowledge of meeting the goal on an outcome of reduced energy cost of walking. 
88. Reisman DS, Rudolph KS, Farquhar WB. Influence of speed on walking economy. Neurorehabil Neural Repair. 2009;23:529-34.

89. Mian OS, Thom JM, Ardigo LP, Morse CI, Narici MV, Minetti AE. Effect of a 12-month physical conditioning programme on the metabolic cost of walking in healthy older adults. Eur J Appl Physiol. 2007;100:499-505.

90. - VanSwearingen JM, Perera S, Brach JS, Wert DM, Studenski S. Exercise to Improve Gait Efficiency: Impact on
Activity and Participation in Older Adults with Mobility Limitations. Phys Ther. 2011;91:1740-51. In a comparative efficacy pilot study in older adults with mobility limitations a task-oriented motor learning intervention targeted to reduce the energy cost of walking reduced disability and improved confidence in walking, while the impairment-based intervention did not reduce cost or disability or improve confidence. Gait speed improved after both interventions. 